\title{
Explore New Ways to Innovate the League Work in Colleges and Universities
}

\author{
YaoYao $^{1}$ and Yuyan Zhou ${ }^{2}$ \\ School of Environmental Engineering, Wuhan Textile University, WuHan 430200, China \\ Student Affairs Office, Wuhan Textile University, WuHan 430200, China
}

yaoyao1145@sina.com;wtuxsc@163.com

\begin{abstract}
Keywords: New media; College student affairs; Characteristic cultural brand
\end{abstract}
\begin{abstract}
Due to its unique functions and features, new media technology not only strongly appeals to college students, but also enriches the mode of the League Work in Colleges and Universities. This paper analyzed how new media application in college student affairs with summarize, case analysis and other methods, This paper suggests that colleges shuold to strength the construction of new media platform; to set up network propaganda team; to create professional and cultural positions; To carry out network public opinion collection, to improve information service mechanism and other strategies on college student development.

With the rapid development of Internet technology, the widespread use of new media such as Weibo, WeChat and APP marks the advent of the new media era. Because of its unique functions and features, new media technology not only strongly attracts college students who are receptive to new things, but also enriches models and platforms for college work and study, which not only provides new opportunities for the development of college students, but also brings new challenges come.

Since the 17th CPC National Congress, the Central Committee of the Communist Youth League has successively issued the opinions on Strengthening the Propaganda and Guidance Work of the Communist Youth League, the Notice on Strengthening the Propaganda Work of the Communist Youth League Network, the General Office of the Communist Youth League about Further Deploying the Network of Good Youth Voices, Cultural Action Notice "and other documents. The Communist Youth League Network Propaganda Teleconference pointed out that building the CYL network propagandist team and doing a good job in propaganda and guidance for the CYL network are the clear tasks assigned by general secretary Jinping $\mathrm{Xi}$ and the party Central Committee to the Communist Youth League in the process of planning to promote the state governing system and the modernization of governance capacity, The new media represented by the Internet profoundly changes the world and affects the young people's new situation. To accomplish the mass work for the youth, the CYL must march into the field of online new media. [1] Therefore, how to give full play to and utilize the advantages of new media, guide the youth, serve the youth, and realize the growth of young students, have become the major problems in the current study of college student affairs.
\end{abstract}

\section{The New Media Content and Features}

UNESCO's definition of new media: "The medium of information transmission based on digital technology and network as a carrier." [2] New media is the fifth medium differing from the four traditionally significant newspapers, radio, TV, and magazines, It is based on digital technology, internet technology to provide information services to the audience emerging media. Based on emerging digital technologies, new media covers digital media, digital newspapers, digital broadcasts, mobile messaging, the Internet, desktop windows and touch media.

The dissemination of new media information mainly shows characteristics of openness, instantness, interactivity and virtuality in the college group study. First, openness. The new media 
technology uses the internet as a medium to break the limitation of time and space, and to solve the restriction of traditional media by time, region and other factors, and to provide the audience with a ready-to-accept and arbitrary information reception. The second is immediacy. The information dissemination under the new media technology has not only got rid of the time and space constraints but also lowered the threshold of information release. People can grasp the latest information and disseminate information through the network anytime and anywhere. The third is interaction. Due to the openness of new media, interactive communication of information can be realized, audiences can change roles at any time, and the media has changed from the traditional point-to-many format to many-to-many format, which promotes the dissemination of information since the media is rich in color And communication; Fourth, the virtual. The new media weaken s and hides the true identity of the information publisher. The information usually exists in a hypothetical state, which makes the entire new media more and more virtual.

\section{New Media Bring Opportunities and Challenges to the College and University Studies}

University students are easy to accept emerging things, the widespread use of new media technology has a profound impact on the thinking, learning and living of young students. The advent of the new media has also enabled young students to diversify their ways of obtaining information and display their individuality. At present, the foundation and core of the college and university student work are to attract and unite the youth, and it is necessary to start from both the thought-guiding and the growing-up service. The arrival of the new media age also continuously enriches the ways and carriers for the college- Jobs provide opportunities for innovation and development as well as challenges.

New Media Bring Opportunities To College League Work. First, interactive exchange for college students to provide discourse space, enhance the function of educating students to learn. The interactive features of the new media can help the CYDF understand and master the trends of the young people in time and analyze the young students' ideological appeals so as to guide and educate the young students more effectively. Youth students can fully express their opinions, exchange ideas and experiences, enhance subjective awareness, strengthen their sense of identity and belonging to the CYL organizations, and integrate the CYL organizations into young people through the help of the official microblogging, blogs and BBS exchange platforms set up by CYL organizations in life.

Second, an open platform enriched the carrier learning group, innovative ways to learn. The new media technology solves the problems of limited space and limited ability of information transfer in CYL work, shows the advantages of large amount of information, abundant forms and rapid dissemination, and enhances the coverage and influence of CYL work. Not only can group workers immediately grasp the fresh information through the application of new media such as the Communist Youth League website and multimedia communication, and conduct positive political education for young people, young members of group members can also learn about the latest group activities through the website of the CYL Group, Thought to arm yourself.

Third, real-time characteristics of the CYL improve the efficiency of CYL organizations, improve CYL style of work. In carrying out the work of the Communist Youth League, the CYL, through its platform of new media, can promptly transmit advanced ideological and political views, special activity materials and various documents to the youth groups timely and timely, and can gradually realize online office automation and online exchanges Exhibitions, online discussions and other new forms of group work, which laid a good foundation for improving the work style of the Communist Youth League.

The New Media to the Mission of Learning Challenges. First, "uncontrolled" access to information hinder the development of college communist youth league ideological guidace. The openness, rapidity and uncontrollability of the new media make the network information uneven. Negative and negative comments, vulgar and violent information are flooding the network, leading to the deviation of the core values of young students. Some young students indulge in Unreal world in the network, loss of judgment and analytical power, and even embarked on the road to crime. The 
past inculcation and preaching teaching methods are no longer suitable for the current situation. How to guide the young students correctly and give full play to the cohesion of the CYL organizations has become a major challenge for the CYL education.

Second, the "Verticality" of information dissemination increases the difficulty of supervising the communist youth league in colleges and universities. The new media technology has the characteristics of virtuality. Its wide application makes information dissemination break the limitation of time and space and form a virtual space. Most students often conduct anonymous or aliased online communication, it is difficult to ensure the authenticity of the communication, [3] the information released by the real or not also increases the difficulty of college students learning to identify information and regulatory information, to the supervision of the Communist Youth League Job poses challenges.

Third, the "diversity" of information technology puts forward higher gequirements on the innovative work methods of communist youth league in colleges and Universities. The new media era Digital technology is widely used, new technologies emerge in an endless stream, the focus of young students to transfer from traditional media to digital media, multimedia applications in their life learning can be seen everywhere, online forums, community stations become their gathering place, they are free to The expression of their own ideas, the unification of past arrangements and the unified guidance of the Communist Youth League in universities in the form of a single form, lack of flexibility and interactivity can no longer meet the needs of young students. Diversified new media technologies have expanded conditions for the work of CYL and proposed new requirements for the ideological concepts, work carriers and work methods innovation of CYL work.

\section{The New Media Environment, College and College Work Innovation Strategy}

To Strengthen the Construction of New Media Platform to Create a Network of Cultural Positions. The new media influences the thinking and cognitive ability of college students through a variety of online channels. Therefore, it is of great significance to guide the network culture in the correct direction and to build the organizational position of the innovation league. Student work should be gradually established to serve student-oriented application platform system, the use of young students love to see the way close to the student life, into the students mind. First, we should strengthen student orientation, employment, psychology, funding and other application systems to improve the use of new media for students to serve the scientific level and enhance students' sense of belonging; the second is to establish a network of new media work in the student work department, School Youth League, school-level student organizations, college student organizations and classes to establish a multi-tiered cross-grid system of school classes to provide a strong support platform for the application of new media to strengthen the thinking of the Communist Youth League leading function; [4] Third, the expansion group Learn the contents and modules of the website, add fresh information and national affairs hot issues, open online salon, academic forums, online essay and other activities, disseminate the party's theoretical policies and ideas, to display the Communist Youth League lively and vivid education content, to create network culture ideas position.

Improve the Quality of Cadres Themselves, the Formation of Network Propaganda Team. In the age of the Internet, the development of college and university studies should regard new media as a breakthrough point in guiding young people's thinking and require CYL cadres to actively learn knowledge, incorporate CYL experience into the learning process, and apply new media technologies flexibly to practical work. The cadres here include not only the instructors who work for the college reunification study but also the student leaders in the student organizations at all levels. By improving the quality of the cadres themselves, they can influence and enhance the ideological quality of the vast majority of young students, and can start from the following two aspects : On the one hand, the model and carrier of innovative training courses have made it more time-efficient and diversified in the form of diversified training contents based on the previous fixed and single teacher lectures and expert lectures, the addition of network distance learning, the 
carrying out of network theme activities and online discussions Attractive; on the other hand, the formation of the Communist Youth League network of propagandists team, covering mission workers, counselors and students backbone, promote the socialist core values and the dissemination of advanced culture, to carry out the network of media guidance work, while establishing network propaganda team WeChat Group, QQ group, to strengthen the communication network of network members.

Relying on the Characteristics of Brand Culture, Create a Professional Culture Position. Although new media platforms and technologies are widely used in the current group study, we can not neglect the content construction of the group study. The content construction of the mission learning is the fundamental, the new media is only a technology and tools, in order to better carry out the mission work, ideological education services. Therefore, under the new media environment, it is necessary to combine traditional media and new media with a focus on building distinctive cultural positions in universities and colleges, applying new media technologies to original characteristic brand culture projects, expanding the influence and appeal of characteristic brand culture, This requires relying on the characteristics of organizations to play the role of the traditional brand culture. Such as the Wuhan University of Culture and environmental protection cultural festival features cultural brand, is one of the top 100 associations - green environmental protection associations based on the theme of environmental protection activities, the festival is based on environmental professional culture-based environmental education, environmental research, environmental DIY, Environmental social practices and other thematic activities, the combination of professional learning and environmental protection activities, activities to enhance the overall ability of students can introduce micro-video propaganda World Earth Day, World Water Day, the use of electronic magazines on the theme of extensive publicity activities, Thereby increasing the influence of leather card culture to attract more young students to participate in activities.

Change the Concept of Work Management, Improve the Information Service Mechanism. The service of young students is an important part of the work of the college and university students. Under the new media environment, the college students are required firstly to change the work mode of unifiedly arranged and carried out activities in the new era to focus on the students' needs and focus on the hot topics of the young students, Social practice and so on, to enhance the attractiveness of the CYL organization. Secondly, the new media technology will be introduced into the daily management to enhance the objective and fair management, and to create a CYL information network. The specific links of the CYL will be assessed and evaluated Join the party, the activities of the declaration, members of the daily registration of information into the network office platform for students to query and apply to solve the problem of office time and improve the effectiveness of management; Third, to change the work of thinking and change in the past group management and young students between the management and Managed relationships respect young students' autonomous access to information and freedom of opinion, and help young students to learn and grow in a new media environment.

To Carry Out Network Public Opinion Collection, Improve the New Media Management System. College students should establish a management mechanism to carry out network public opinion collection and guidance, with a focus on influential websites, blogs, BBS and other platforms. First of all, the Propaganda Department, the Academic Affairs Office, the school youth league committee and the defense units should form an effective linkage to establish a network of public opinion crisis management mechanism and improve the "information collection - crisis identification - development forecast - decision - handling" five links, using the campus portal , Microblogging, counselors blog and other network platforms, the students concerned about the hot issues and emergencies initiative, timely response, publish positive authority information to guide the development of public opinion, so as to effectively intervene in the crisis of public opinion; Second, strengthen the group learning workers, The backbone of the student cadres as the main force of public opinion supervision team building, training a supervisory team of students with strong thinking, strengthen the supervision of the purpose is not to limit the freedom of speech of 
young students, but timely and effective grasp of student ideological and dynamic broad and reasonable guidance of public opinion Finally, the development of new information management techniques to prevent the spread of bad information from the technical level, the CYL organizations can also use the new technology to analyze the youth-related data on the network to form a special research report to provide a reference for network public opinion management.

All in all, with the continuous development of Internet technology and multimedia technology, new media technology will be more widely used. New media technology is a double-edged sword, how to correctly and effectively use new media in the process of college group study In order to better guide and educate students, we must innovate the working methods and carriers of university study around the growth of students around the premise of being student-centered, and explore a scientific management mode to help young students in a new era to tap and showcase their own Style.

\section{Acknowledgements}

This paper is a periodic achievement of an ideology and politics special research project of Hubei provincial educational department entitled "exploration on higher education synergy system in practice based on environmental clubs" (project No:1617YA02) as well as Hubei Province college student work boutique project "professional community services to explore the growth mechanism of university students" (project No: 2017XGJPF3018)

\section{References}

[1] Communist Youth League network publicity work teleconference -China Youth Network http://news.youth.cn/wztt/201405/t20140529_5278183.htm

[2] New Media http://baike.baidu.com/subview/339017/5403053.htm?fr=aladdin

[3] N.Zhao. New media on the work of college students impact analysis, Science Education . (2014) No.3, p.239-242

[4] J.P.Chen,Influence of New Media on Youth League Work in Colleges and Universities and Its Countermeasures, Youth \& Juvenile Research,vol77,( 2010)No.3,p54-56. 